proceeded to the dirty section, and after being bathed and then disinfected at the cleansing station moved into the clean section, where they remained until they embarked for Eng. land. Each complete cleansing installation was designed to provide for the bathing and disinfection of the clothes of 3,000 men in from Io to I I hours. These installations were provided on a basis for dealing with 50 per cent more men than the camp accommodated to allow for breakdowns and overlapping. The bathing arrangements included dressing rooms, hot sprays (24 per 3,000 men per day), and drying rooms, with accessories such as towel rooms, dirty underclothing and clean underclothing stores. Bathing and disinfection could be carried out simultaneously throughout the day.

For disinfection the hot-air disinfector designed by Major Orr, of the Canadian Army Medical Service, was adopted. This type of disinfector was highly efficient and satisfactory in working owing to the continual passage of a current of hot air through the chambers. On account of the low specific heat of air a rapid circulation of hot air is necessary to raise the temperature of the clothing to the lethal temperature within a reasonable time. The articles to be disinfected for each man were: (1) tunic, (2) trousers, (3) shirt, (4) vest, (5) greatcoat. The men were supplied with clean underclothing, of which a stock of 12,000 pieces was kept at the cleansing station. The underclothes worn by the men on arrival at the baths, such as shirts, undervests and pants, were despatched to area laundries, where they were disinfected in steam chambers, washed, and returned to the cleansing station for reissue.

The men brought down their blankets with them, and these were disinfected and re-issued to the camps. The blankets used in the dirty section of the camps were disinfected at least once a week, or oftener, if in the opinion of the Medical Officer it was considered necessary. In the clean section, the blankets were also disinfected weekly. Facilities for disinfecting the blankets were afforded by working the hot air disinfectors during the night hours. At any one installation, 3,000 blankets could be disinfected in 3 to 4 hours, allowing at least half an hour in the disinfecting chambers. Medical inspection was carried out as the men passed through the baths by a medical officer, and cases of scabies or other diseases were sent to a hospital specially allotfed to receive men from camps of demobilisation. As the stay in camp was liable to be tedious, sports, games and other recreations and entertainments were organised.

\section{THE REFRACTORIES INDUSTRIES (SILICOSIS) SCHEME, I9I9.}

By Chas. L. Sutherland, M.B., D.P.H., District Tuberculosis Officer, Yorks, West Riding.

The Refractories Industries (Silicosis) Scheme was brought into force under the Workmen's Compensation (Silicosis) Act, Igrg. At present it provides for compensation in one class of workers only, that of miners in ganister and workers in silica brick works. As there is a likelihood of this or some similar scheme being extended to other workers exposed to dust-discases, it may interest your readers to go over some of the points in connection with the present scheme. I do not propose to go into the clinical aspects of the question.

The finance of the Scheme is dealt with by a limited company called the "Fund," which is supported by contributions from the employers, each employer paying on the basis of a percentage of the wages earned by the employees covered. All those firms who deal with materal containing 80 per cent of silica are brought within the Scheme.

It is to be noted that the Scheme is the first attempt to avoid the County Courts in compensation cases. The compensation is fixed by a committee composed of equal numbers of workmen and employers under a neutral chairman. To this committee the "Appointed Medical Officer" sends the certificates of disability; and these certificates are final in that they cannot be challenged and the matter taken to court.

Work under the Scheme falls upon the Tuberculosis Officer of the area, who becomes the appointed medical officer. His duties during the first year of the operation of the Scheme have been to examine all workers in the industries, to examine all new workers, and to examine all claimants for compensation. The medical officer has to suspend any worker whom he believes to be suffering from silicosis to a degree that would be dangerous if he continued at the vork. To assist him on this point he may make use of the X-ray, and if still in 
cloubt he may refer the case to a "Medical Advisory Committee."

To protect workers who have spent over twenty years in this kind of work, there is a clause which states that they may not be examined unless they present a written request to be examined.

The examination of all workers and especially of new workers involves the examination of a large number of people who can have had no possible chance of developing silicosis. Still if a case of silicosis did turn up the worker would be suspended in the ordinary way, but the statement on the certificate that the condition was not contracted in the industries clears the "Fund" of responsibility. In this connection it may be mentioned that the medical officer has no power to deal with a case of tuberculosis unless silicosis is present. Indeed the writer has met with cases of tubercle who have "come out to an open-air job."

The examinations are conducted at the work and employers have very definite instructions as to the accommodation to be provided. The results of each examination are noted on a special form; and a note of any action taken, made in two copies of a book called the "Workers' Register." One of these is kept by the employer, the other by the man as his evidence that he comes within the scope of the Scheme, should he wish to claim compensation at any time.

Much attention has been drawn to diseases caused by dust inhalation, and it is to be hoped that the results of the examinations made under this Scheme may elucidate some of the problems presented by the condition. The exact relationship of silicosis and tuberculosis, for instance, has not yet been settled.

WE much regret to record the death of Dr. Philip William Gowlett Nunn, for upwards of forty years medical officer of health for Bournemouth, until his retirement in 1911.

AT their last meeting, the Holborn Borough Council considered a letter from the Ministry of Health, suggesting that a salary of $£ 800$ per annum, proposed to be paid the new medical officer of health, was not sufficient remuneration for a whole time officer. A similar communication had been received from the Society of Medical Officers of Health. The Council decided to fix the salary at $f 1,000$, inclusive of bonus.

\section{SOCIETY OF MEDICAL OFFICERS OF HEALTH.}

\section{Council Menting.}

A meeting of the Council was held at the house of the Society on Friday, January 2Ist. Dr. Charles Sanders (Vice-President) was in the chair, and there were present: Drs. Wheatley, Auden, Clements, G. F. Buchan, Kirkhope, Wilshaw, Howarth, Blackett, Ellis, Stocks, Gibbons Ward, Edmund Smith, Veitch Clark, Joseph, and Barlow.

Apologies for absence were received from Lieut.-Col. Herbert Jones, Drs. Chalmers, Cates, Kerr, Lyster, Snell, and Kenwood. The Executive Secretary was directed to send a message of sympathy to the President, who was unable to be present owing to illness.

The minutes of the last meeting having been approved and signed, Dr. James Wheatley asked permission to refer to the decision of the Council on December 17th, 1920, regarding propaganda work in reference to dietary and food values. He suggested that the Council should not leave it to individual members to support such important movements, and he proposed to take an early opportunity of asking the Society to make a corporate pronouncement in this connection.

Correspondence. - (1) From the Central Council for District Nursing in London asking the Society to appoint four representatives to serve on that body. for the year from July 1st, 1921. Resolved: That Prof. H. R. Kenwood, Dr. William Butler, Dr. Charles Porter, and Dr. Joseph Priestley be re-elected as representatives of the Society on the Central Council for District Nursing in London. (2) From the British Dental Association, asking for the co-operation of the Society in securing the adoption of a scale of salaries for Dental Officers by Local Authorities. Resolved: That the communication of the B.D.A. be referred to the Salaries Committee for early consideration. (3) From the Medical Defence Union, inviting the Society to take action in regard to the claim of a medical officer who had been refused a bonus by his local authority. Resolved: That as the claimant has apparenty no legal claim against the local authority, intervention by the Society could serve no useful purpose. (4) From the Home Counties' 